\title{
TABLE
}

DES MATIẼRES CONTENUES DANS CE VOLUME.

Page.

Préface...................................... 2

Coup D'GIL SUR LES DIVERS GOUVERNEMENS DU CANADA, DEPUIS

LA Cession................................ 5

De la Constitution du Canada..................... 9

PREMIEิRE PARTIE.

Des drotts particuliers des habitans du Canada........ 11

SECONDE PARTIE.

Forme du gouvernement.......................... 16

CHAPITRE PREMIER.

Du pouvolr Legislatif.................... 17

De l'Assemblé Legislative.................. 18

Des Elections............................. 19

Des Officiers-Rapporteurs..................... il.

Devoirs des Officiers-Rapporteurs................. 21

Du Clere d'Election. ......................... $i b$.

Nomination............................ 22

Ouverture et tenue du poll......................

Deputés-Officiers-Rapporteurs et Clers de poll........... 23

Qualification des Electeurs......................24

Enrégistrement des votes-formalités................ 26

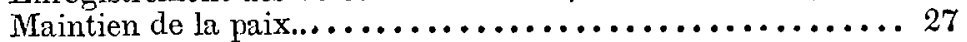

Dispositions contre la corruption.................

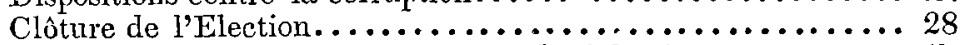

Ce qui doit être fait après la clôture de l'élection......... ib.

Du Conseil Légrslatif........................ 29

Du Gouverneur, comme partie du pouvoir Législatif. . . . . . 31

Du Parlement, ou des trois branches de la Législature réul-

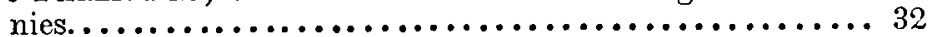

Ordre des séances-bills-pétitions etc.............. 34

Des Comités............................... 38

Des Officiers et employés des Chambres...............

Liste Civile - Subsides - Revenus et depenses de la Pro-

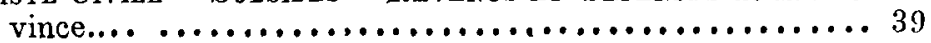


Du pouvoIR ExÉcutif.....................4

Du Conseil Executif-sa composition-ses atTributions.. 45

Président du Conseil.........................48

Procureurs-Généraux......................... ib.

Solliciteurs-Généraux....................... 49

Secrétaire-Provincial.......................

Receveur-Général.......................... 50

Inspecteur-Général........................ 51

Comnissaire des Terres de la Couronne............... 52

Commissaires des Travaux Publics.................. 53

Secrétaire du Gouverneur..................... 54

\section{CHAPITRE TROISIEME.}

De Gouvernement Responsable............... 55

CHAPITRE QUATRIẼME.

Court parallèle entre le Gouvernement d'Angleterre

et le Gouvernement du Canada............... 59

TROISIÈME PARTIE.

Dt pouvolr JUDICIAIRE..................... 63

TRIBUNAUX DU BAS-CANADA.

Cours des Commissaires.........................65

Cours de Circuits............................69 69

Cour Supérieure......................... 70

Cour du Banc de la Reine ou d'Appel................. 72

Des Juges de Paix et des Tribunaux Criminels......... 73

Sessions de Quartier.......................... 74

Cour Criminelle du Bane de la Reine............... 75

APPENDICE.

DE LA CORRESPONDANCE aVEC LE gOUVERNEMENT........... 77

Des Requêtes-Des Lettres........................ . . . . . .

Des Assembles Publiques...................... 80

Comment doivent être conduites les Assemblées Publiques. . . 8 84

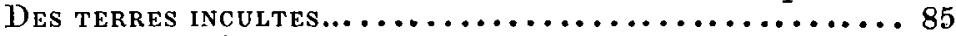

Articles des Capitulations, dont les dispositions sont en vigueur.............................. 88

Capitulation de Québec........................

Capitulation de Montréal. ........................ 
Traite de PaIx de 1763.........................91

ACTE DE QUEBEC............................ 92

Acte Constitutionnel de $1791 \ldots \ldots \ldots \ldots \ldots \ldots \ldots \ldots \ldots . \ldots 9$

ACTE D'UnION, TEL QU'AMENDE.................... 100

Acte pour octroyer une Liste Civile à Sa Majesté...........119

Acte relatif à l'usage de la langue Anglaise... . . . . . . . . 125

Regles permanentes de l'Assemblee Législative, concernant les bills privés...........................126

Liste des Gouverneurs du Canada, depuis la cession........129

Liste des Membres de la Chambre dªssemble du BasCanada, deputs l'Etablissement de la Constitution jus-

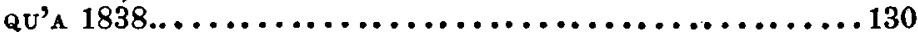

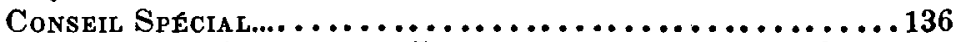

Membres de l'Assemble Legislative dU Canada, depuis l'Union jusqu'à nos jours....................... 137

Liste des Membres du Consell Legislatif du Bas-Canada, jusqu'à la suspension de la Constitution (1838)..........139

Membres du Conseil Legislatif du Canada, depuis l'Union.140

Liste des Membres du Conseil Executif du Bas-Canada, avant 1 Union...............................141

Membres du Conseil Executif du Canada, depuis l'Union...142

FIN DE LA TABLE。 